\title{
Problem hydromorphic soils in north-east Thailand. 1. Environment and soil morphology
}

\author{
Robert Brinkman, A. G. Jongmans and R. Miedema \\ Department of Soil Science and Geology, Agricultural University, Duivendaal 10, \\ Wageningen, Netherlands
}

Accepted: 28 March 1977

Key words: paddy soils, weathering

\section{Summary}

The Roi Et soil, a Gleyic Acrisol (FAO, 1974) is one of the main soils on the extensive seasonally wet, low terrace in north-east Thailand. The soil appeared poor in the field, producing traditionally low yields of one paddy rice crop per year. With fertilizers and dry-season irrigation, problems of water-logging, surface salinity and acidity caused poor germination and low yields of both rice and dry-season dryland crops.

$\mathrm{X}$-ray stereo radiographs, macro- and micromorphological data indicate that a sequence of processes has taken place in this soil, including perforation and homogenization by roots and soil fauna; iron mobilization and redistribution; clay translocation; alteration of clay and formation of secondary silica; and surface slaking alternating with ploughing. The clay translocation appears to be fossil. Two stages of iron mobilization under (seasonally) wet conditions are indicated, the later one, with clay alteration, continuing to the present. The soil has a considerable macroporosity, due to worms and termites, mainly in the subsoil. The ploughpan and the deep subsoil have low porosity.

\section{Introduction}

There are large areas of seasonally wet, acid soils on low terrace landforms in south-east Asia, particularly in north-east Thailand (Fig. 1). These belong to the Gleyic Acrisols among the soil units of the Soil Map of the World (FAO, 1974 and 1976); the Aquults (part: Aqualfs) in the Soil Taxonomy (Soil Survey Staff, 1975); and the Low Humic Gley soils in older classifications (e.g. Moormann \& Rojanasoonthon, 1968).

Most of this land is used for a single paddy rice crop per year, in the monsoon season. Generally, no fertilizers are used and yields are low (about 1 ton paddy per hectare). After provision of dry-season irrigation water in many locations, crop 
diversification is attempted and yield increases are expected, but problems of salinity, acidity and water saturation have limited the degree of success achieved.

The present paper deals with the environment and soil morphology of Roi Et series, a major soil on the low terrace. Subsequent papers will discuss physical and chemical aspects, mineralogy and genesis of the Roi Et soil (Brinkman, 1977), and the nature of the saline-acid conditions occurring on the low terrace, the possible mechanisms underlying them, and a set of proposals for reclamation, improvement and management of the soils for irrigated double cropping (Brinkman \& Dieleman, 1977).

\section{Methods}

Soil description is according to FAO (undated); the horizon designations are according to FAO (1974). Thin sections from undisturbed blocks were prepared according to Fitz Patrick (1970). Micromorphological terms are according to Brewer (1964).

$\mathrm{X}$-ray transmission stereo radiographs were prepared of 5 -mm thick sections from plastic-impregnated undisturbed blocks according to Rogaar \& Thiadens (1975). Voids and impregnating plastic are X-ray transparent and show dark on $\mathrm{X}$-ray film; iron (as well as, for example, calcium in calcareous soils) strongly attenuate the radiation so that nodules are blank on the film image; silicon and aluminium cause moderate attenuation (grey tones). In contrast to thin sections or polished surfaces, which give information about a single plane, stereo radiographs allow direct three-dimensional observation of void patterns and concentrations of, for example, iron or calcium in a volume of soil.

\section{Field data}

\section{Distribution, landforms and environment}

Gleyic Acrisols (Roi Et and similar series) are the main soils on the extensive, nearly level, low terraces in south-east Asia (Fig. 1, map unit 2). Only where the terrace sediments are derived from adjacent calcareous or basic rocks, Gleyic Luvisols or Vertisols locally replace the Gleyic Acrisols. The low terraces also contain occasional long, narrow, shallow depressions (channel remnants?), and sandy outcrops of higher terrace material and levee remnants. The low terraces adjoin lower-lying, younger, less weathered hydromorphic soils (map unit 3) in generally narrow river plains and in the wide alluvial plain around Tonle Sap. The low terraces extend upstream between older, generally more sandy, well-drained terraces, hills and mountains (map unit 1).

North-east Thailand has a tropical monsoon climate, with annual rainfall about $1400 \mathrm{~mm}$, more than $80 \%$ of which falls in the months May through September. Potential evapotranspiration is about $1000-1300 \mathrm{~mm}$, but the upper horizons dry out strongly and actual evapotranspiration is very low in the later part of the dry season without irrigation. During the rainy season, the soils on the low terrace are 


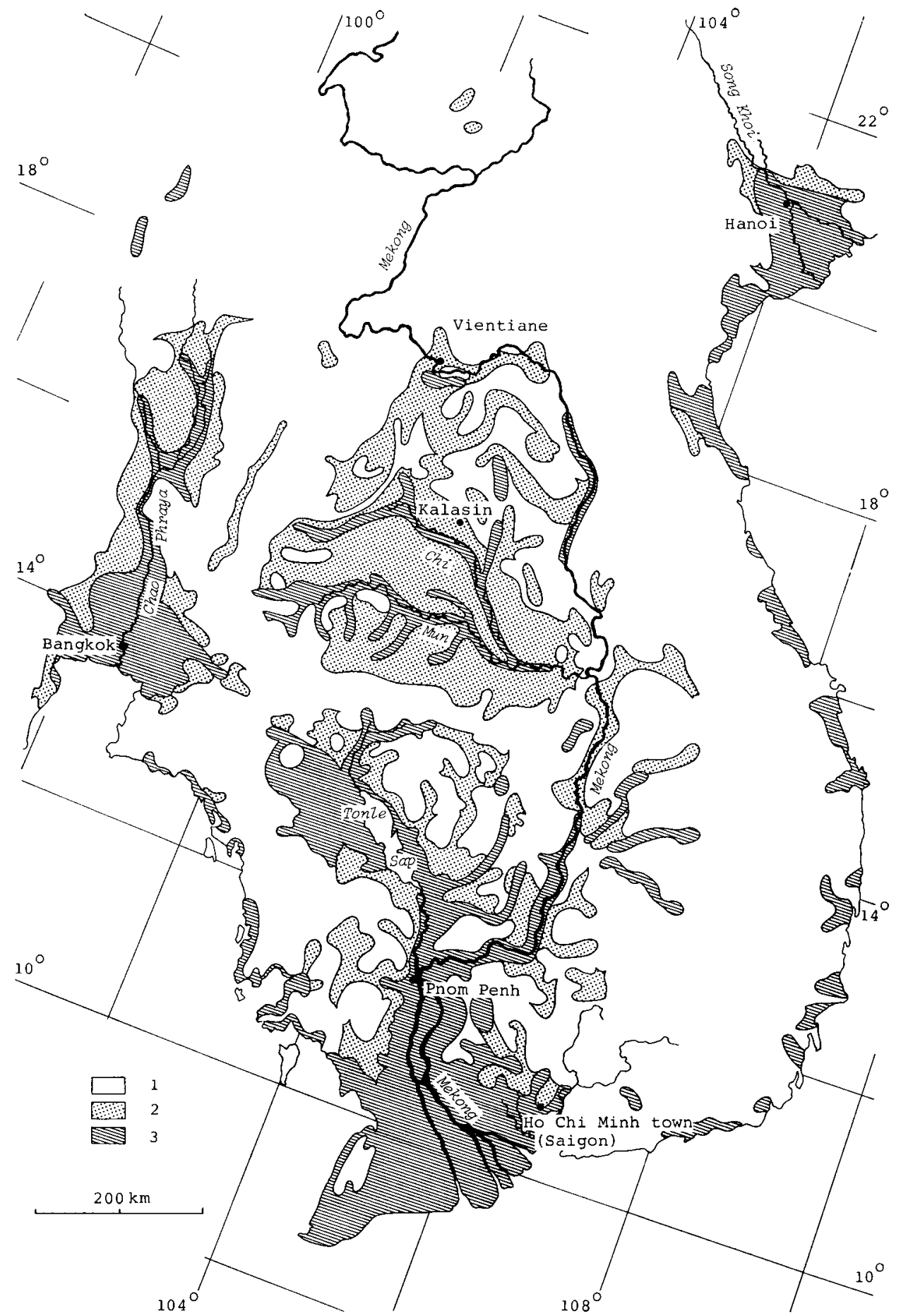

Fig. 1. Distribution of Gleyic Acrisols in the Mekong basin and surroundings. Simplified from FAO (1976), with some information from van der Kevie (1972) and Moormann \& Rojanasoonthon (1968). Blank (map unit 1): mountains, hills and high, well-drained terraces; stippled (2): low terraces with Roi Et and similar weathered, acid hydromorphic soils (Gleyic Acrisols); hatched (3): younger alluvial plains. 


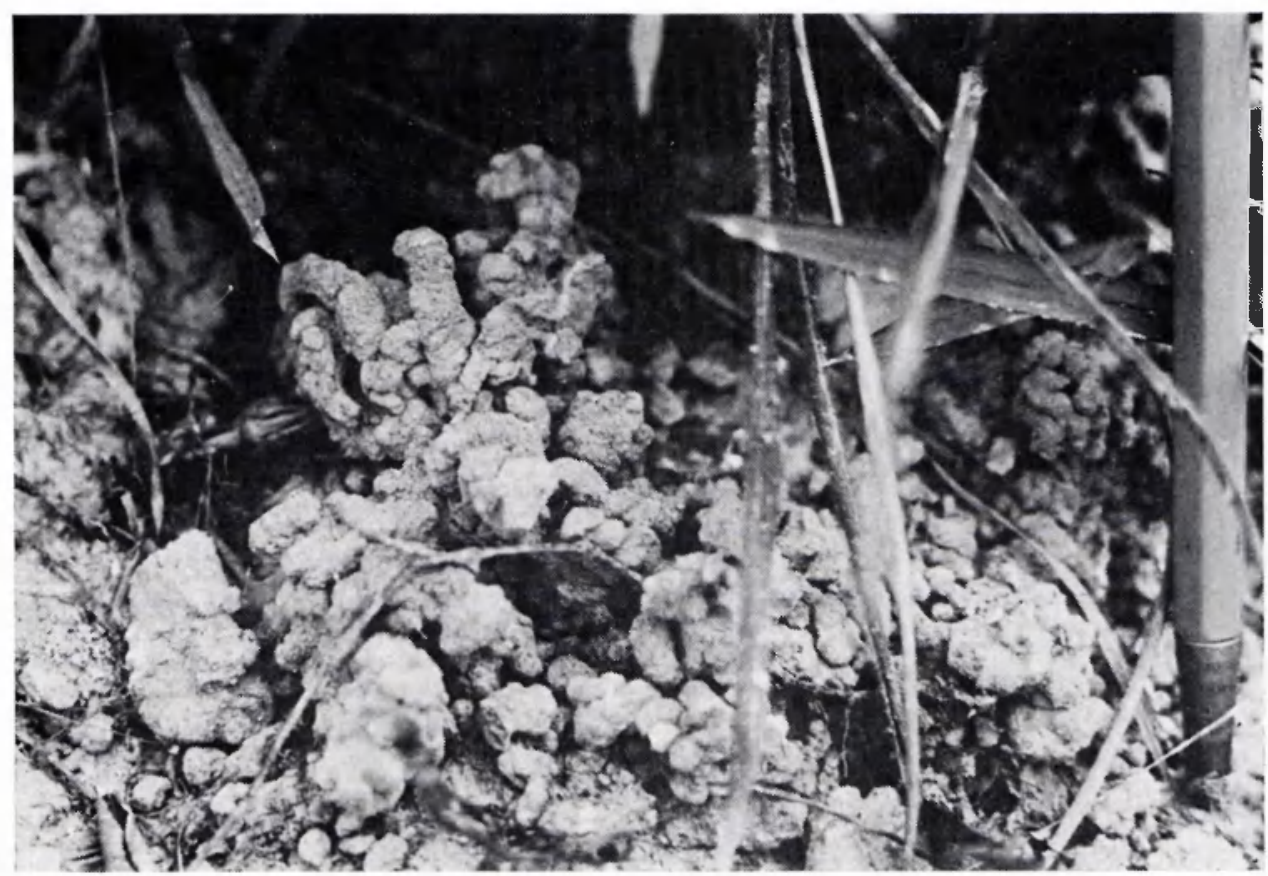

Fig. 2. Worm casts in field margin adjoining bund (Pencil (right) $8 \mathrm{~mm}$ thick.)

inundated by (very slowly moving) rain water, part of which is retained by low bunds around the fields.

In spite of the inundation, the soils are apparently not reduced throughout their depth, because there are occasional small and larger trees in fields and frequent small ones on field bunds, as well as (rare) termite mounds in the fields and abundant small 'towers' of earthworm casts in the field margins, adjoining bunds (Fig. 2). Only where the soil is perennially saturated, for example by water leaking from irrigation field ditches, some dead and dying trees were observed. No trees were seen in the irregular, narrow, perennially wet seepage strips locally adjoining higher terraces.

Most of the low terrace (landscape Fig. 3) is used for a single crop of local longgrained paddy rice, as are the younger soils in the river plains. Forest covers part of the higher terraces and hills, as well as sandy outcrops in the low terrace and high levee remnants in the river plains. Part of the higher land is used for shifting or permanent cultivation of dryland crops.

\section{The soil}

A profile of Roi Et series is discussed, as an example of the main soils occurring in the low terrace of north-east Thailand and similar soils in other parts of the Mekong basin. A detailed description is given at the end of this paper. 
The soil (Fig. 4) has a grey (light) silt loam plough layer and ploughpan (Apg) over a grey clay loam upper subsoil $(\mathrm{Eg})$, all with fine mottles, overlying a grey loam deeper subsoil $(\mathrm{Bg})$ with strong coarse mottles, extending beyond $2 \mathrm{~m}$. The coarse mottling consists of soft nodules; few hard nodules occur in the upper $\mathrm{Bg}$ horizon.

The consistence is friable throughout, but ploughpan and substratum are firm in place. The structure is massive in the plough layer and ploughpan, and grades to very coarse prismatic and coarse angular blocky at depth.

Fine and medium tubular pores are common in most of the profile except for the ploughpan and the substratum below $1.4 \mathrm{~m}$ which have few pores. There are occasional coarse tubes and round and dome-shaped chambers, indicative of worm and termite activity. Roots extend to $0.6 \mathrm{~m}$ depth.

There are thin and, in the substratum, also medium and thick cutans on ped faces and in pores, and locally similar material filling the lower end of pores (Fig. 5). Cutan material is grey and appears silty or very fine-sandy to the touch.

\section{X-ray stereo radiography}

Stereo radiographs of vertical sections from different depths were used to obtain an insight into the spatial distribution of pores and of total iron in the profile. The

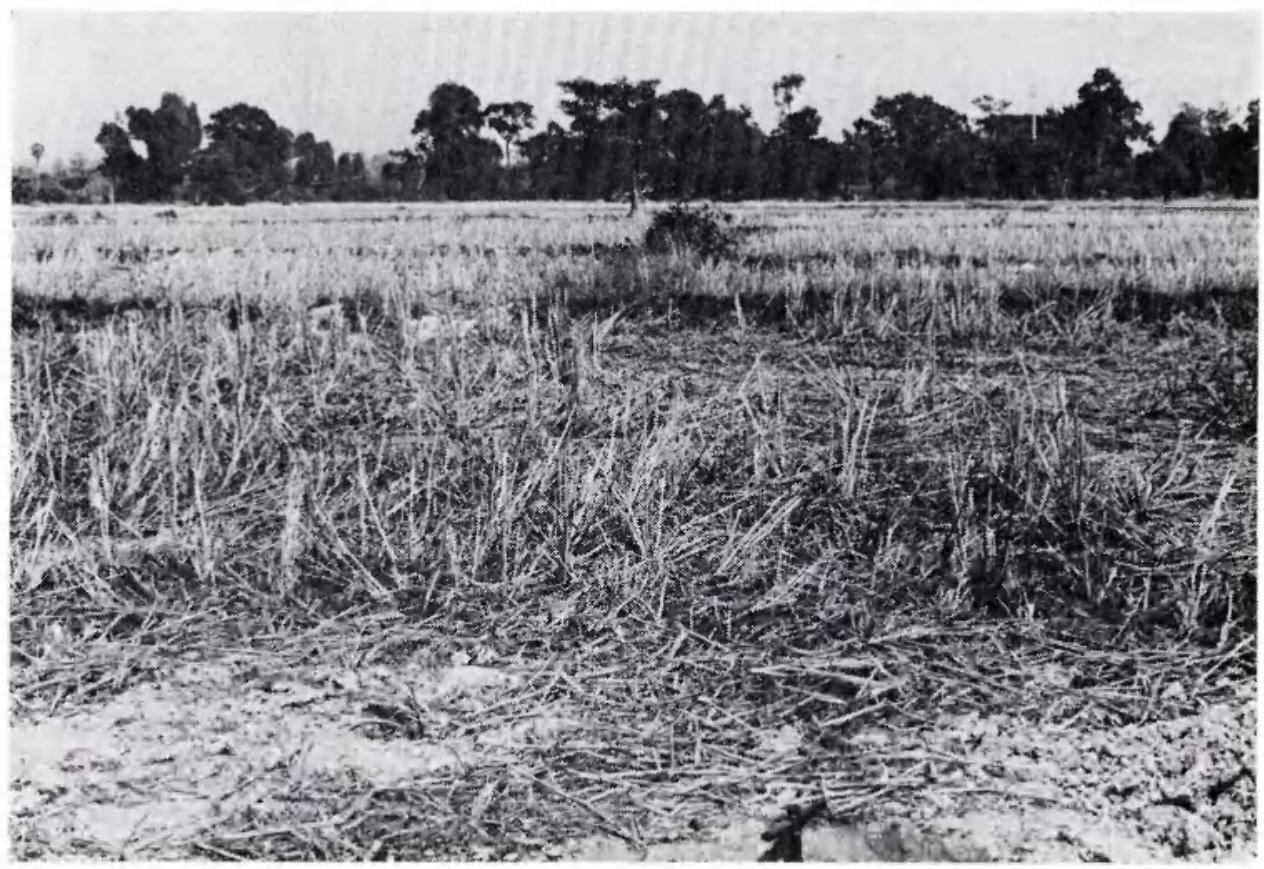

Fig. 3. Landscape of Roi Et series north-east of Kalasin; profile site and some excavated material in foreground. 


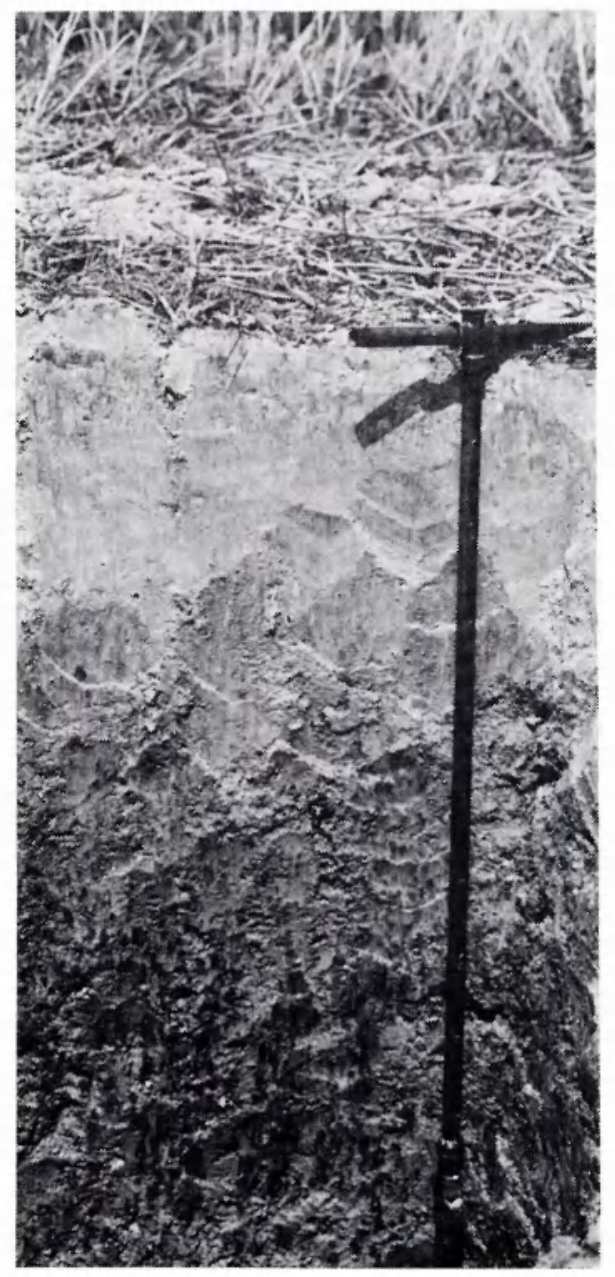

Fig. 4. Soil profile, Roi Et series. Auger $1.2 \mathrm{~m}$ long. Profile described at end of paper.

information was checked by observation of polished surfaces of the same sections under incident light.

\section{Pore structure}

The Eg horizon (Fig. 6A) has abundant, mainly continuous, very fine random and fine mainly vertical tubes with twisting courses. Part of these are dendritically branching. The very fine tubes and at least the dendritic fine ones were probably produced by plant roots. There are also common medium $(2-4 \mathrm{~mm})$ simple or forking tubes in all directions. Part of the latter, and some coarse tubes (up to $8 \mathrm{~mm}$ ) are filled with rather loosely packed fine granular material (aggrotubules). These coarse and medium tubes, and part of the fine ones, were probably produced by worms and termites. 


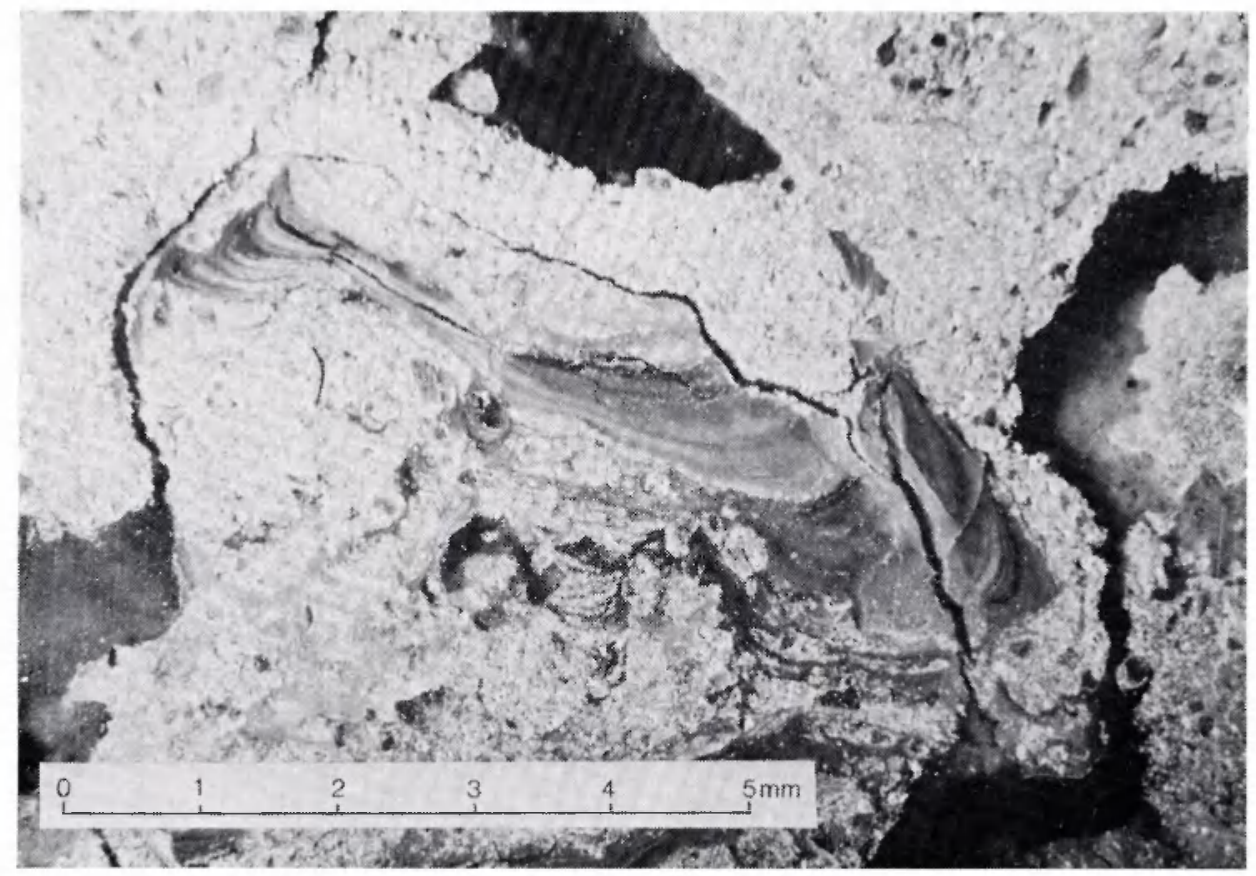

Fig. 5. Laminated infilling in bottom of former void. $185 \mathrm{~cm}$ depth. Impregnated section, $5 \mathrm{~mm}$ thick. Incident light. Fallen groundmass on top of the infilling. Remnant of void at top of figure.

Few continuous tubes are found in the Bg horizons (fig. 6B). In the upper $\mathrm{Bg}$ horizons, there are many vughs: discontinuous remnants of random very fine tubes, and of fine and medium tubes flattened into subhorizontal lenticular shapes. Common coarse (up to $8 \mathrm{~mm}$ ) irregular voids each branch into several medium and fine tubes in all directions. Most pores occur in the parts low in iron; the iron-rich parts only contain occasional pores. Very few fine cracks (craze planes) are visible in the upper $\mathrm{Bg}$ horizons.

The lowest $\mathrm{Bg}$ horizon has generally common, mainly discontinuous, very fine random pores, and locally many in parts low in iron. There are common discontinuous fine and medium (1-4 mm) random tubes as well, but most of these are partly or completely filled by stratified or massive material and occasional aggregates. Most of these tubes in the material low in iron appear distorted. Few very fine and fine, and very few medium mainly vertical and some horizontal cracks (craze planes) were observed in the lowest horizon.

The predominance of vughs and distorted tubes in the B horizons shows that after a period in which mainly biotic activity influenced these lower horizons, physical processes have become dominant, presumably due to water saturation alternating with strong desiccation. Biotic activity has remained dominant in the $\mathrm{Ag}$ and $\mathrm{Eg}$ horizons. 

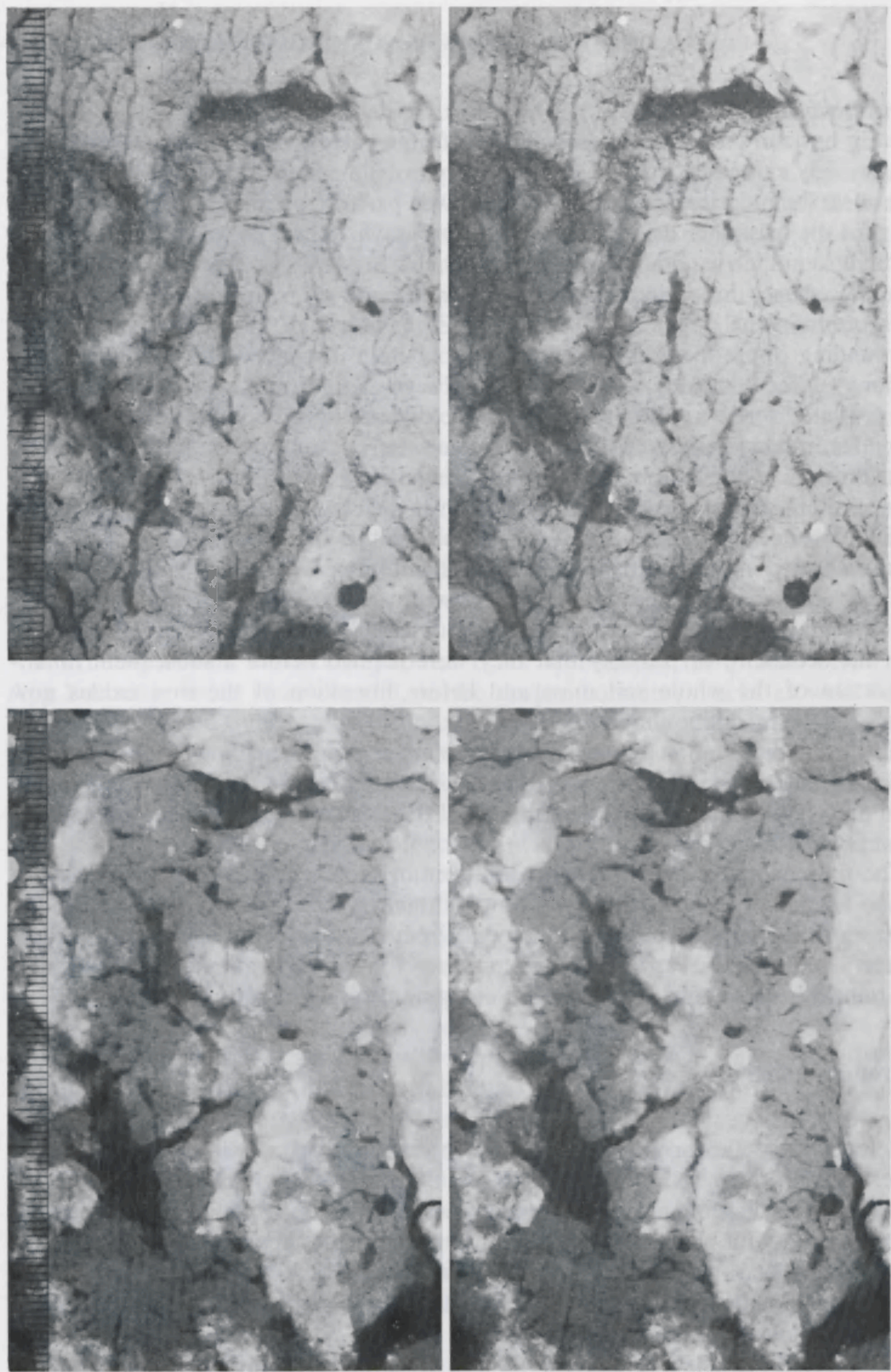

Fig. 6. X-ray stereo radiographs of $5 \mathrm{~mm}$ thick, vertical sections of the $\mathrm{Eg}$ and $\mathrm{Bg}$ horizons. A three-dimensional view may be obtained by use of a pocket stereoscope or a pair of lenses about +4 diopters $(\mathrm{f}=25 \mathrm{~cm}$ ) or stronger. Millimetre scale on left. Upper pair: Eg horizon, $50-59 \mathrm{~cm}$ depth; lower pair: Bg horizon, $96-105 \mathrm{~cm}$ depth. Black: voids; dark grey: soil material low in iron; light grey: soil material higher in iron (neoferrans in Eg, mottles and probably original soil material in $\mathrm{Bg}$ horizon); white: concentrated iron oxides (nodules). 


\section{Iron distribution}

The Eg horizon contains common thin neoferrans along very fine pores, and common weakly expressed (iron content not very high) medium and coarse iron mottles with clear boundaries, increasing in the lower part of the horizon: probably remnants of the prismatic shapes observed further down. There are occasional fine and medium round ferric nodules with mainly sharp boundaries.

Many coarse, discontinuous prismatic shapes with clear, locally gradual boundaries occur in the upper Bg horizons. These have a higher iron content than the surrounding (more disturbed) material, and contain irregularly distributed concentrations of ferric oxides, less than one to several millimetres in size. There are few scattered ferric nodules (1-4 mm diameter) with sharp boundaries, both in the more disturbed material and in the prism remnants.

In the lowest $\mathrm{B}$ horizon, the prismatic shapes are larger still, about $5 \mathrm{~cm}$ wide. They contain mainly evenly distributed iron, and few medium concentrations with gradual boundaries. Occasional ferric nodules with sharp boundaries occur in the more disturbed material surrounding the prismatic shapes.

The occurrence of round ferric nodules with abrupt edges both in the disturbed material and in the prism remnants suggests that they may have been brought in with the sediment, or possibly that they were formed before a subsequent homogenization of the whole soil mass and before liberation of the iron oxides now present in the prismatic shapes.

The even distribution of iron in the prismatic shapes, without higher concentrations along the margins, suggests that the iron-rich areas are dissolution remnants from an originally ferruginous soil mass, and that iron redistribution played a minor part in their formation.

The presence of organic matter in the form of root remnants may have been the reason for activity of soil fauna, resulting in homogenization of part of the soil mass to a relatively great depth. This homogenized material containing some organic matter would then be far more liable to seasonal water saturation and to reduction and removal of iron oxides than the adjoining undisturbed parts.

\section{Micromorphology}

Skeleton grains throughout the profile consist of quartz, with sporadic heavy minerals. The quartz is corroded, and cracks in many grains contain iron oxides. The grain distribution pattern is mainly random, locally with clusters in the $\mathrm{Bg}$ horizons, and with a banded distribution pattern in the Apg horizons. The lowest horizon contains some angular, strongly birefringent grains $0.3-2 \mathrm{~mm}$ in size, locally covered by iron oxides, and showing exfoliation (fanning out) along their edges. These probably are pedorelics.

The plasma consists of clay minerals and a white opalescent material resembling secondary silica. In the Apg horizon, which contains some organic matter as well, there is less plasma than further down.

Biogenic voids throughout the profile consist of channels, vughs and intercon- 
nected vughs. Simple packing voids are found in the ploughed layer, and craze planes throughout the profile below the Apg horizons.

Common aggrotubules with diameters between 0.3 and $1 \mathrm{~mm}$ were observed in the Apg horizons, and few in the Eg. The latter contains occasional argillans and neoferrans. The upper $5 \mathrm{~mm}$ of the Apg1 largely consists of fecal pellets with a higher organic matter content than the rest of the horizon.

Redistributed iron oxides occur in two forms. Channel neoferrans, about 20-50 $\mu \mathrm{m}$ thick, occur in the Apg2, Eg and EBg horizons and in the lowest $\mathrm{Bg}$ horizon, at about $1.8 \mathrm{~m}$ depth. These locally cover argillans.

Orange to dark red ferric nodules with diffuse to abrupt boundaries are present throughout the $\mathrm{EBg}$ and $\mathrm{Bg}$ horizons, with a maximum about $1 \mathrm{~m}$ depth. Part of these have a droplet structure (Hamilton, 1964). The droplets are red, birefringent and of the order of $1-2 \mu \mathrm{m}$ in size. These nodules generally contain illuviation cutans. A second type of dark red nodules up to several $\mathrm{mm}$ diameter, with abrupt boundaries and without illuviation cutans, occurs in the EBg and Bg1 horizons. These locally also have a droplet structure. Some cracks in the second type of nodules contain recrystallized iron oxides. Illuviated clay occurs in a shrinkage crack around one nodule.

Illuviation cutans and some papules occur throughout the profile below the Apg horizons, lining channels and, in the deeper horizons, cracks as well. Some cutans are covered by secondary iron oxides. The cutans are mainly argillans, low in iron, part with a continuous orientation (birefringent), part grainy and nearly isotropic. The ratio of birefringent to isotropic, grainy material decreases significantly ( $\mathrm{P}<0.05$ one-sided) from 1.1 in the deepest horizons to 0.8 in the Apg and Eg horizons (Fig. 7). Argillans enclosed within ferric nodules tend to be more highly birefringent and less grainy than those occurring in the grey parts of the soil. Some cutans contain thinly stratified grainy material. Some cutans are partly birefringent, partly isotropic and grainy (Fig. 8), with gradual boundaries crossing the direction of stratification. Papules comprise $27 \%$ of the grainy features and $16 \%$ of the birefringent ones. This suggests gradual conversion of birefringent into grainy material concurrent with continued clay illuviation.

The grainy material is strongly white opalescent in incident light (Fig. 8B) and dark in transmitted light (Fig. 8C); individual grains are of the order of $0.5 \mu \mathrm{m}$ in size. When viewed at high magnifications $(\times 600$ to $\times 1000)$ the grains are transparent and appear (weakly) birefringent. The grains may be clay-size quartz: see also the section on clay mineralogy in Brinkman (1977). The significance of birefringent and grainy argillans in a surface-water gley soil is discussed in Brinkman et al. (1973).

The Apg horizons contain a considerable proportion of stratified (banded) remnants of slaking crusts. The upper part of the pieces has the finest texture and generally contains much material that is white opalescent in incident light; the lower part is gradually coarser. The pieces contain occasional vesicular voids. In a few of the larger channels in deeper horizons there are cutans consisting of alternating silt and clay strata (Fig. 5): probably slaked material from the surface. 
ROBERT BRINKMAN, A. G. IONGMANS AND R. MIEDEMA

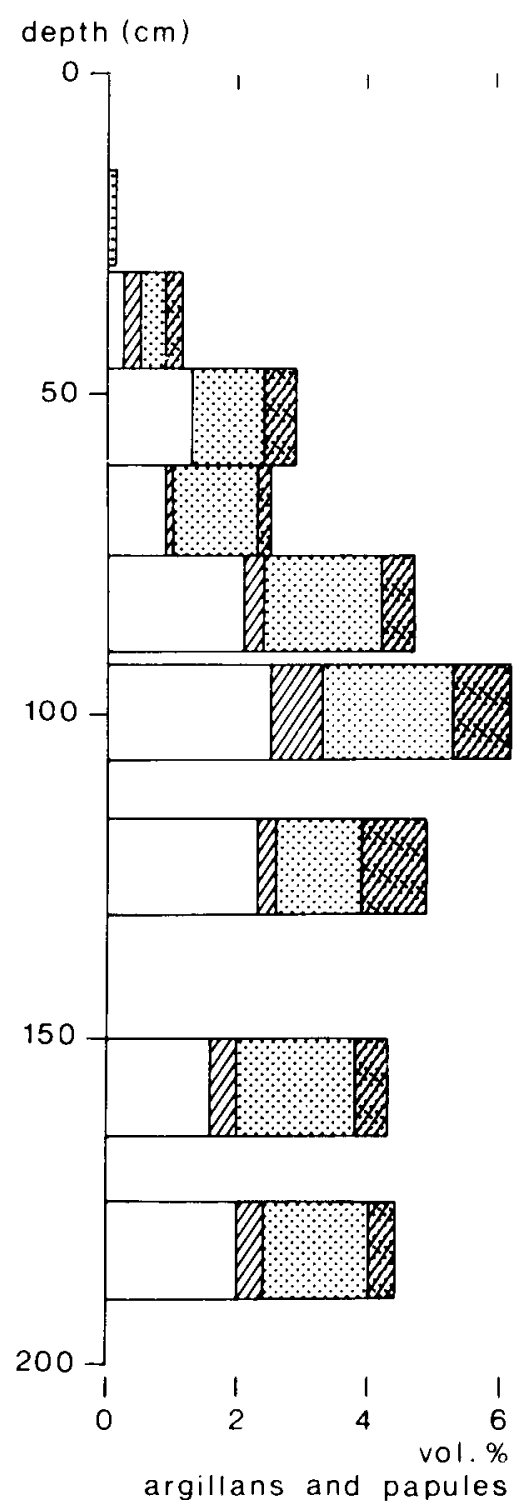

thin section horizon

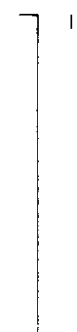

72070

Apg 1

71

$\operatorname{Apg} 2$

72

$\mathrm{Eg}$

73

74

EBg

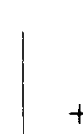

$+$

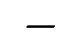

75

$\mathrm{Bg} 1$

$+\quad 76$

-

$\mathrm{Bg} 2$

77

(1)

$+$

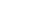

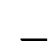

78

$\mathrm{Bg} 3$

$\%$ argillans and papules

ratio birefringent/grainy

Fig. 7. Content of argillans and papules at different depths. Blank: birefringent argillans; hatched: birefringent papules; stippled: isotropic, grainy argillans; stippled and hatched: isotropic, grainy papules. 
PROBLEM HYDROMORPHIC SOILS IN NORTH-EAST THAILAND. 1
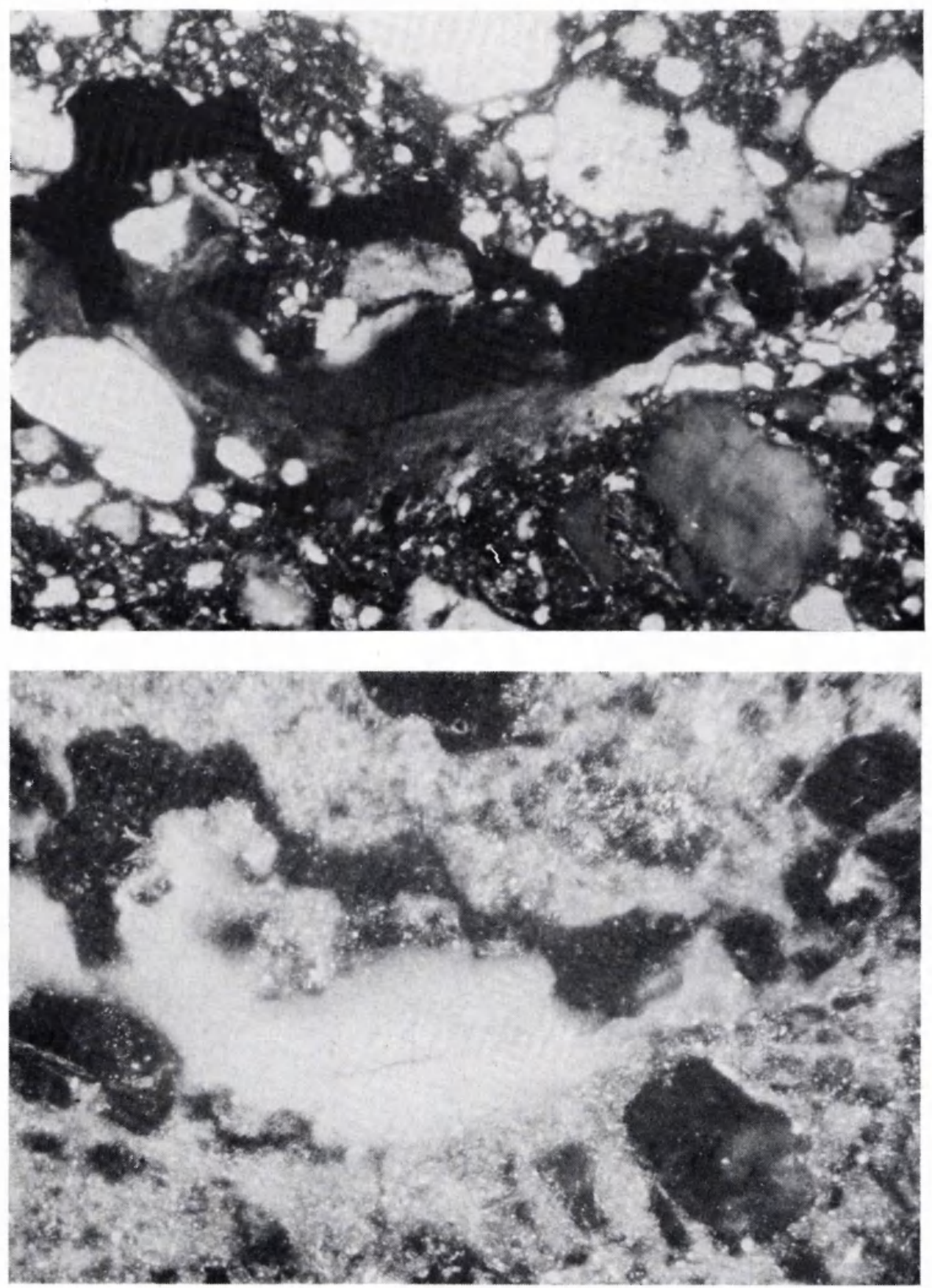

Fig. 8. Grainy argillan in thin section. $76 \mathrm{~cm}$ depth. A (top): between crossed polarizers; B (bottom): in incident mercury light. 

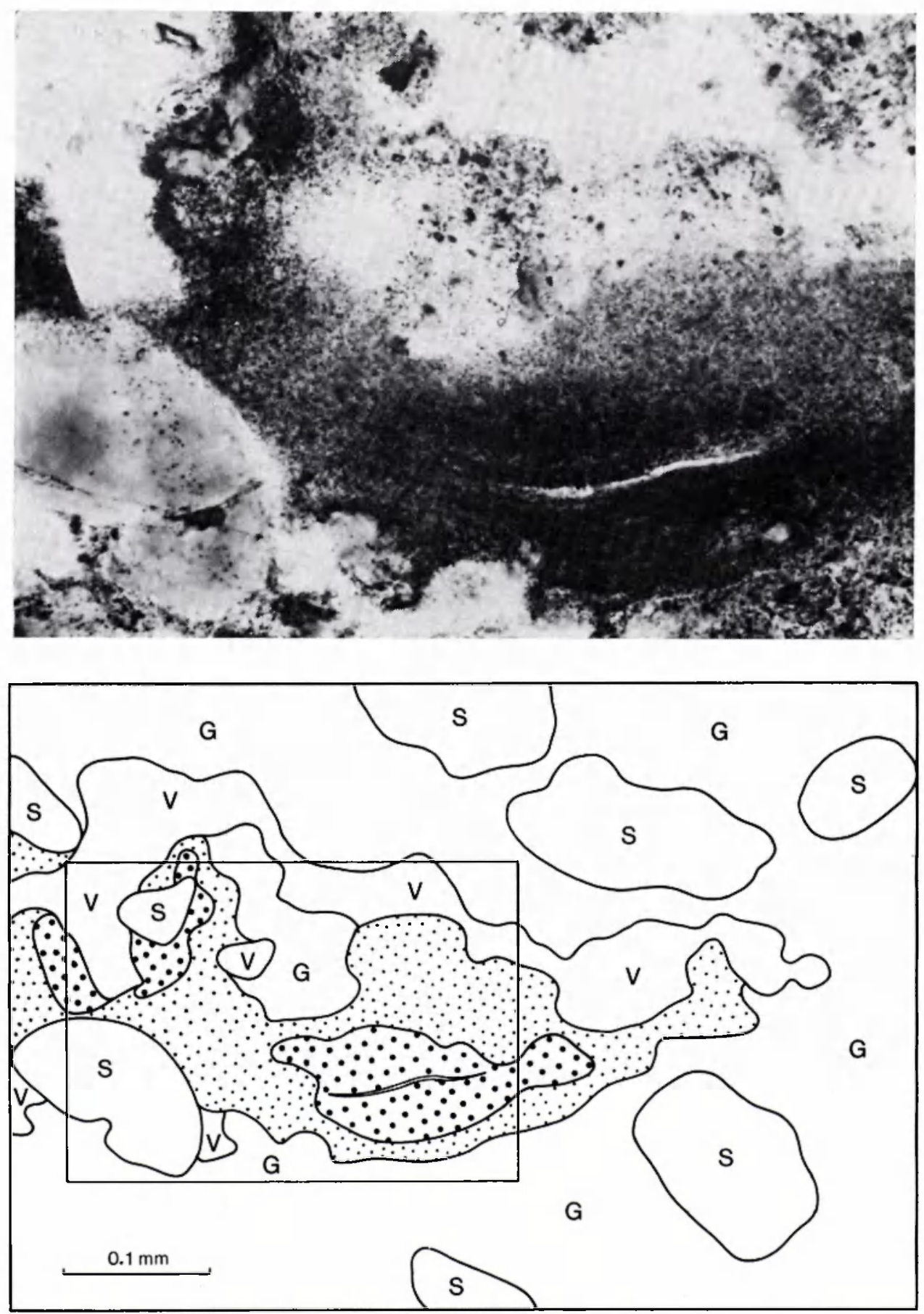

Fig. 8 (continued). C: between parallel polarizers, detail; D: outline sketch of A and B (box indicates area of $\mathrm{C}$ ). $\mathrm{S}=$ sand grains; $\mathrm{G}=$ ground mass; $\mathrm{V}=$ voids. Light stipple: weakly birefringent argillan, moderately grainy; heavy stipple: isotropic argillan, very grainy. 


\section{Possible sequence of processes}

The observations indicate that several processes have taken place in this soil. These include corrosion of quartz grains and deposition of iron oxides in the cracks; perforation and homogenization by roots and soil fauna; iron redistribution; clay eluviation with illuviation over a considerable range of depths; alteration of clay and formation of secondary silica; and surface slaking alternating with ploughing. These processes have not all operated concurrently.

The corroded quartz grains with iron oxides in cracks are similar to the skeleton grains which we observed in well-drained Ferralsols (Oxisols), and unlike those in seasonally wet soils. They may have been brought in the sediment as preweathered material.

The iron nodules without enclosed argillans or papules are indicative of an early phase of alternating reduction and oxidation, before the start of clay translocation (possibly in a ground-water gley situation, shortly after deposition).

A considerable amount of perforation and homogenization must have taken place rather early during soil development, before and during the period of clay translocation. Most of the illuviated clay occurs as argillans on walls of channels and cracks, and occasionally in aggrotubules; relatively little has been reworked into papules. Biotic homogenization is continuing up to the present, as shown by the small towers of worm excreta (Fig. 2) along the field margins, and the occasional earthworms observed during excavation of the soil profile.

The presence of birefringent argillans in protected locations and partly birefringent, partly isotropic and grainy ones (Fig. 8) in other places indicates that clay translocation started before clay decomposition. Translocation must have continued while the decomposition process was active, because there are argillans with laminations of grainy material as well. The argillans (as well as the plasma) are increasingly grainy toward the surface, and few argillans or papules were observed in the Eg horizon, in spite of its maximal clay content. The Eg horizon in this profile may therefore have developed in the upper part of a former textural B horizon. The clay in the upper horizons is almost completely grainy, as clearly observed in the fine-textured parts of the slaking crusts. The features suggest that clay decomposition continued after the end of clay translocation, and occurred (or still occurs) mainly in the upper horizons.

Iron redistribution into nodules and occasional neoferrans due to seasonal reduction and oxidation probably started (again) at, or preceding, the beginning of clay decomposition, because illuviated clay enclosed in nodules is more birefringent and less grainy than that in the remainder of the thin sections. The occasional neoferrans around channels in the annually ploughed Apg1 show that the iron redistribution continues until the present.

The remnants of slaking crusts in the Apg horizons are recent and are produced by the annual ploughing and puddling for rice cultivation. The occasional cutans and channel infillings consisting of stratified silty and clayey material in deeper horizons (Fig. 5) are probably caused by sediment-laden water moving down large channels during the puddling operation. 
Most of the biotic activity is presently concentrated in the Apg1, as shown by the abundant fecal pellets near the soil surface, probably due to the prevalence of recent rice roots in that horizon and the low porosity of the ploughpan.

\section{Description of Roi Et series}

Roi Et series (Thailand), FAO/Unesco Soil Units (FAO, 1974): Gleyic Acrisol; USDA Soil Taxonomy (Soil Survey Staff, 1975): Paleaquult. Profile KAL-1, examined 18 March 1972 by R. Brinkman.

The site

Location near Kalasin, north-east Thailand. About $5 \mathrm{~km}$ north-east of Kalasin town, along road to Thanon Thinanon, about $50 \mathrm{~m}$ east of road, about $1 \mathrm{~km}$ from the nearest large outcrops of higher terrace. Map reference Thailand 1:50 000 scale, sheet 5760-III (Changwat Kalasin), U.S. Army Map Service and Royal Thai Survey Dept. 1960. $\mathrm{Km}$ grid $1819.8 \mathrm{~N}, 345.1$ E. About $16^{\circ} 27^{\prime} \mathrm{N}, 103^{\circ} 33^{\prime}$ E. Elevation $145 \mathrm{~m}$ above mean sea level.

Landform and slope: level, low terrace, slope about $0.1 \%$ to the east. Fields with bunds $30-40 \mathrm{~cm}$ high. Rare termite mounds, abandoned, about $0.8 \mathrm{~m}$ high. Occasional 'towers' of worm excreta, $5-10 \mathrm{~cm}$ wide and $5-20 \mathrm{~cm}$ high, in field margins immediately adjoining field bunds.

Vegetation/land use: transplanted rice (local long-grain variety), grown in the rainy season without fertilizers and without irrigation. Yields reported of the order of 1 ton/ha. Generally fallow in the dry season. Very locally, small patches of dry-season dryland crops near homesteads, irrigated by hand from wells. About $2 \mathrm{~km}$ west of this site, there is an experimental irrigation scheme of a few hundred hectares. Occasional, locally common trees on field bunds, very few in fields.

Climate: tropical monsoon climate (Köppen Aw). Mean annual temperature $27^{\circ} \mathrm{C}$, coldest month $22^{\circ} \mathrm{C}$, hottest month $30^{\circ} \mathrm{C}$. Precipitation $1370 \mathrm{~mm} /$ year, wettest month about $300 \mathrm{~mm}$, driest month 1-3 mm. Potential evapotranspiration $1000-1300 \mathrm{~mm} /$ year ( 3 stations around Kalasin).

\section{General information on the soil}

Parent material: 'low terrace', a low, nearly level river terrace of uncertain age, late Pleistocene or older judging from soil development.

Drainage poor. Internal drainage slow due to low porosity of deep substratum (below about 1.5 metres); external drainage very slow due to the nearly level surface with field bunds. Seasonally flooded to shallow depth for 3-5 months. Moisture conditions in the soil: Apg1 dry, moist below.

Depth of ground water about $1.8 \mathrm{~m}$ at the site, but reported average below three metres at the end of the dry season. About $0.3 \mathrm{~m}$ (estimate) above ground level at the height of the rainy season. Ground water remains at or less than $0.5 \mathrm{~m}$ below the surface throughout the year in narrow strips along outcrops of a higher, sandy terrace and in places with excessive dry-season irrigation, as practised about $2 \mathrm{~km}$ west of this site. 
No surface stones or rock outcrops are present; there is no evidence of erosion.

There is no salt or sodicity (alkali) or soluble acid at the site or in most of the area. In places with a permanently high water-table there is surface salinity. On slight elevations and on slightly higher marginal strips of the low terrace along outcrops of a higher, sandy terrace, the surface salinity is extreme and there are toxic concentrations of soluble aluminium and ferric iron in the surface soil and salt crust, with recorded local $\mathrm{pH}$ values about 3 .

Human influence comprises low bunds, about $30-40 \mathrm{~cm}$ high, around rice fields, a ploughpan due to puddling for rice, and locally (not at this site) a permanently high water-table due to excessive dry-season irrigation water.

\section{Brief general description of the profile}

Deep, poorly drained, grey silt loam to loam with a distinctly mottled subsoil and strongly mottled substratum containing soft and hard ferric nodules. Structure is weak; the soil is porous to about $1.5 \mathrm{~m}$ depth but massive and apparently very slowly permeable below. Fine roots extend to about $0.6 \mathrm{~m}$. Note: alteration under hydromorphic conditions (loss of iron) appears to be dominant in the present $\mathrm{Eg}$ horizon (probably a former part of a textural B) as well as in the Apg horizons.

\section{Profile description}

Apg1, 0-16 cm. Pinkish grey (7.5 YR 6/2) moist light silt loam; few fine distinct strong brown mottles mainly along pores; massive with bits, mainly lenticular, of grey slightly finer textured material (ploughed-in remnants of slaking crusts produced by puddling?); moist very friable; common, locally many fine roots; clear, wavy boundary. Sample No 72-119; thin sections $72070(0-15 \mathrm{~cm}), 72080(0-8$ $\mathrm{cm}, 15 \mathrm{~cm}$ wide), 72081 (about $5 \mathrm{~cm}$, horizontal plane).

Apg2, 16-26 cm. Pinkish grey (7.5 YR 6/2) moist light loam (very fine sandy); few fine distinct reddish yellow mottles mainly along pores; massive; moist very friable, slightly firm in place; few fine and very fine mainly vertical tubular pores; few, locally common, fine roots; clear, wavy boundary $(24-28 \mathrm{~cm})$. Sample No 72-120; thin sections $72071(15-30 \mathrm{~cm}), 72082$ (about $20 \mathrm{~cm}$, horizontal plane). $E g$, 26-61 cm. Pinkish grey (10 YR 6/2) moist clay loam; common, locally few fine distinct strong brown mottles, mainly on pore faces; weak very coarse and coarse prismatic; moist friable; common medium and many fine mainly vertical tubular pores, locally scattered coarse tubular pores and dome-shaped chambers, about $5 \mathrm{~cm}$ wide and $3 \mathrm{~cm}$ high; broken thin cutans in tubes; locally fine granules (excreta) in pores; common fine mainly vertical roots; gradual smooth boundary. Samples No $72-121(26-45 \mathrm{~cm}), 72-122(45-61 \mathrm{~cm})$; thin sections part of 72071 $(15-30 \mathrm{~cm}), 72072(31-46 \mathrm{~cm}), 72073(46-61 \mathrm{~cm})$.

$E B g, 61-75 \mathrm{~cm}$. Pinkish grey (7.5 YR 6/2) moist loam with very fine sand fraction; common fine distinct reddish yellow mottles; weak coarse subangular blocky; moist friable; few medium and common fine tubular pores in peds and on faces; generally broken but locally continuous medium and thin cutans in pores, locally cutans of fine sand, cutans are slightly greyer than mass; few medium and fine soft ferric nodules; common fine remnants of excreta, same colour as mass; no roots; gradual 
smooth boundary. Sample No 72-123; thin section $72074(60-75 \mathrm{~cm})$.

Btg1, 75-96 cm. Pinkish grey (10 YR 7/2) moist loam, ped faces with slightly less clay; many coarse prominent brownish yellow very soft ferric nodules with dark red to red (10 R 3/6-2.5 YR 4/6) centres and few medium dark reddish brown (2.5 YR $3 / 4$ ) hard ferric nodules, all in peds, ped faces pinkish grey; moderate very coarse and coarse prismatic breaking into weak subangular blocky; moist friable, firm in place; few medium, common fine tubes in and on faces, common medium and fine tubes and few medium vughs in mass; continuous moderately thick cutans (gleyans ${ }^{1}$ of material from the surface horizon?) on most vertical faces and tubes, broken thin cutans in vesicular pores, on horizontal and locally on vertical faces; few medium hard nodules; locally fine granular excreta; no roots; gradual wavy boundary. Sample No 72-124; thin sections $72075(75-90 \mathrm{~cm})$, part of $72076(92-107$ $\mathrm{cm})$.

Btg2, 96-140 $\mathrm{cm}$. Grey (10 YR 6/1) moist loam, ped faces with slightly less clay; many coarse prominent red and dark red (2.5 YR 4/8 and $10 \mathrm{R} \mathrm{3/6)} \mathrm{soft} \mathrm{nodules}$ some with a reddish yellow rim or parts, and common coarse distinct reddish yellow soft nodules, all nodules in peds, ped faces pinkish grey (7.5 YR 7/2), locally grey; moderate coarse prismatic breaking into moderate coarse and weak medium subangular blocky; moist friable, firm in place; few medium, common fine tubes in ped faces, common medium and fine tubes and few fine to medium vughs in peds; continuous moderately thick cutans (gleyans) on faces and in tubes; many coarse soft nodules; locally in tubes fine and very fine excreta; no roots; diffuse boundary. Sample No 72-125; thin sections $72076(92-107 \mathrm{~cm}), 72077(116-131 \mathrm{~cm})$.

Btg3, 140-200 cm. Pinkish grey 7.5 YR 7/2) moist loam; many coarse and medium distinct strong brown and reddish yellow mottles, in part soft nodules, locally mainly in lower part common medium and coarse prominent red soft nodules; moderate very coarse prismatic and very coarse and coarse angular blocky; moist friable, mottles and larger aggregates firm, very firm in place; few fine and very fine tubes in faces, few fine and common very fine tubes in peds, locally few medium and fine round chambers; continuous thin cutans on ped faces and pores, with mottles shining through; locally silty material accumulated in bottom of pores; no roots. Samples No 72-126 $(140-170 \mathrm{~cm}), 72-127(170-200 \mathrm{~cm})$; thin sections $72078(150-165 \mathrm{~cm}), 72079(175-190 \mathrm{~cm})$.

\section{Acknowledgments}

We thank Dr R. Dudal and Mr G. M. Higgins, FAO, Rome, for the opportunity of the field study; Mr G. J. van de Waal for the preparation of thin sections; $\mathrm{Mr}$ H. Rogaar for X-ray transmission stereo images and help in their interpretation;

1 Gleyans is the name provisionally given to gleyed ped or pore cutans occurring in seasonally flooded soils (Brammer, 1971). The cutans are typically thicker than true argillans and comprise silt and mica as well as clay and humus. Their colour is that of the overlying surface horizon and it is assumed that they flow, or are injected, down voids from the puddled and reduced ploughed horizon under conditions of seasonal flooding. Their presence is not diagnostic for an argillic horizon, though they may mask the presence of true argillans. 
Miss P. J. Petersen and Mrs A. C. H. Bosch-van den Brink for typing the manuscripts; Mr O. D. Jeronimus for drafting the illustrations of these papers; and Mr Z. van Druuten for photography.

\section{References}

Brammer, H., 1971. Coatings in seasonally flooded soils. Geoderma 6: 5-16.

Brewer, R,, 1964. Fabric and mineral analysis of soils. Wiley, London, $470 \mathrm{pp}$.

Brinkman, R., A. G. Jongmans, R. Miedema \& P. Maaskant, 1973. Clay decomposition in seasonally wet, acid soils: micromorphological, chemical and mineralogical evidence from individual argillans. Geoderma 10: 259-270.

Brinkman, R., 1977. Problem hydromorphic soils in north-east Thailand. 2. Physical and chemical aspects, mineralogy and genesis. Neth. J. agric. Sci. 25 (in press).

Brinkman, R. \& P. J. Dieleman, 1977. Problem hydromorphic soils in north-east Thailand. 3. Saline-acid conditions, reclamation and management. Neth. J. agric. Sci. 25 (in press). FAO (A. J. Smyth), undated (1966). Guidelines for soil profile description. FAO, Rome, 53 pp. FAO, 1974. FAO-Unesco soil map of the World, Vol. I. Legend. Unesco, Paris, 59 pp.

FAO, 1976. FAO-Unesco soil map of the World. Sheet IX. South-east Asia. Unesco, Paris. Fitz Patrick, E. A., 1970. A technique for the preparation of large thin sections of soils and unconsolidated materials. In: D. A. Osmond \& P. Bullock (Ed.), Micromorphological techniques and applications, p. 3-13. Technical Monograph 2, Soil Survey of England and Wales, Rothamsted Exp. Station, Harpenden.

Hamilton, R., 1964. A short note on droplet-formation in iron crusts. In: A. Jongerius (Ed.), Soil micromorphology, p. 277-278. Elsevier, Amsterdam.

Kevie, W. van der, 1972. Descriptive legend for the general soil map for the lower Mekong basin. Appendix I of Final Report of the Soils Consultant. United Nations Committee for Coordination of Investigations of the Lower Mekong Basin. ESCAP Secretariat, Mekong Committee, Sala Santitham, Bangkok.

Moormann, F. R. \& Santhad Rojanasoonthon, 1968. Soils of Thailand, with soil map at 1 : 1250 000. Soil Survey Report No 72, Dept. of Land Development, Ministry of National Development, Bangkok.

Rogaar, H. \& R. A. H. Thiadens, 1975. X-rays applied to the study of the pore structure in soils. Neth. J. agric. Sci. 23: 321-333.

Soil Survey Staff, 1975. Soil Taxonomy: A basic classification for making and interpreting soil surveys. U.S. Dept. Agric. Handbook 436. U.S. Government Printing Office, Washington, D.C., 754 pp. 